\title{
SUSCETIBILIDADE EROSIVA NA BACIA DO CÓRREGO PEDRINHAS EM SILVÂNIA-GO
}

\author{
Larissa Gonçalves Arcanjo dos Santos ${ }^{\text {(a) }}$, Andrelisa Santos de Jesus ${ }^{(b)}$ \\ (a) Instituto de Estudos Sócio Ambientais, Universidade Federal de Goiás, larissagoncalvesufg@ gmail.com \\ (b)Instituto de Estudos Sócio Ambientais, Universidade Federal de Goiás, andrelisa.jesus @ gmail.com
}

\section{EIXO: BACIAS HIDROGRÁFICAS E RECURSOS HÍDRICOS: ANÁLISE, PLANEJAMENTO E GESTÃO}

\begin{abstract}
Resumo
Este trabalho é resultaddo de uma pesquisa diagnóstica e prognóstica do meio físico da bacia do Córrego Pedrinhas em Silvânia-GO. A bacia estudada localiza-se na porção Central do município e possui uma área de $8,5 \mathrm{~km}^{2}$. Essa área representa boa parte da área urbana além de conter pastagem e agricultura. No local existem muitos processos erosivos que estão se tornando um problema para a cidade, uma vez que os fatores que contribuem para esse cenário como desmatamento, urbanização e impermeabilização do solo podem influenciar a ocorrência desses processos. Diante disso, despertou-se o interesse em compreender a suscetibilidade erosiva da área por meio da análise do meio físico. A classe de suscetibilidade à erosão laminar que predomina na área é a classe pouco suscetível com $85,7 \%$ e os locais que correspondem a maior suscetibilidade à erosão linear são as áreas urbanas e pastagens.
\end{abstract}

Palavras chave: Bacia Hidrográfica, Suscetibilidade, Erosão.

\section{Introdução}

A erosão é o processo de "desagregação e remoção de partículas do solo ou de fragmentos e partículas de rochas, pela ação combinada da gravidade com a água, vento, gelo e/ou organismos (plantas e animais)" (IPT,1995). A análise dos atributos morfométricos do relevo permite avaliar o seu grau de energia e sua suscetibilidade à ocorrência de processos erosivos e deposicionais (MOREIRA \& NETO, 1998). Nesse sentido, Castro \& Xavier (2004) apontam que a suscetibilidade está relacionada "ao seu potencial erosivo natural. O município de Silvânia localiza-se no Sudeste goiano e dista aproximadamente $80 \mathrm{~km}$ de Goiânia. A bacia hidrográfica do córrego Pedrinhas está situada na porção central do município e possui uma área de $8,5 \mathrm{~km}^{2}$, inseridos num retângulo envolvente com $44,7 \mathrm{~km}^{2}$ (Figura 1).

A cidade de Silvânia tem enfrentado muitos problemas relacionados à processos erosivos tais como riscos em edificações, assoreamentos e inundações. Jesus (2014) e Affonso (2014) identificaram e cadastraram vários processos erosivos em Silvânia tanto na área urbana como em áreas periurbanas demonstrando que os processos erosivos tem sido uma dos problemas enfrentados 


$\begin{aligned} & \text { XVII Simpósio Brasileiro } \\ & \text { de Geografia Fisica Aplicada }\end{aligned}$
$\begin{aligned} & \text { I Congresso Nacional } \\ & \text { de Geografia Física }\end{aligned}$

pela cidade. Desse modo, esse trabalho tem como objetivo analisar a suscetibilidade erosiva da área de estudo analisando os atributos do meio físico e de uso e cobertura do solo quanto ao surgimento de processos erosivos.

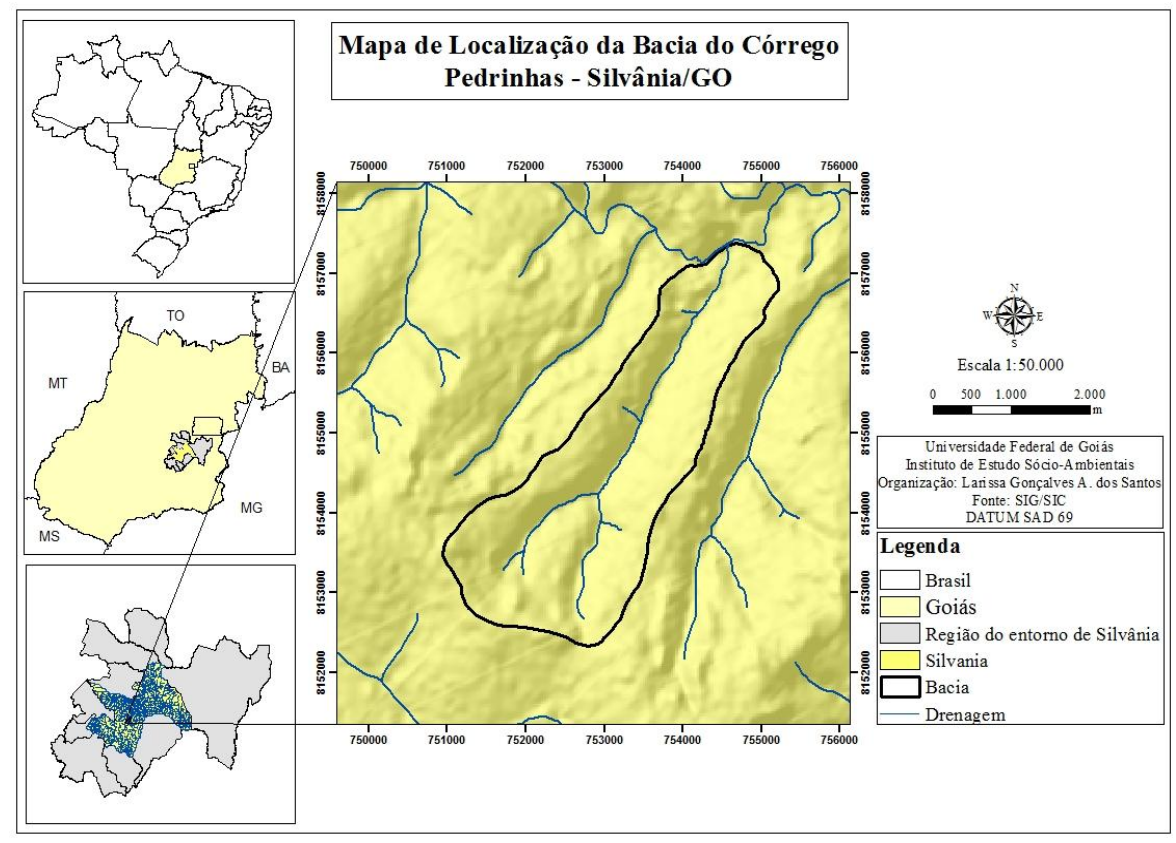

Figura 1 - Mapa de Localização da Bacia Hidrográfica Pedrinhas-Silvânia/GO.

\section{Materiais e métodos}

A base cartográfica desse trabalho constituiu-se da aquisição da imagem de radar do SRTM (Shuttle Radar Topography Mission) e da imagem de satélite SPOT do ano de 2011 com uma resolução espacial de 2,5 metros, adquirida do banco de dados do Laboratório de Geomorfologia, Pedologia e Geografia Física (LABOGEF-IESA/UFG), o que foi útil para a elaboração do mapa de uso do solo e o refinamento das drenagens na área de estudo. A imagem de radar SRTM, foi obtida do TOPODATA (Banco de dados Geomorfométricos do Brasil) com resolução espacial de 30 metros. A partir dessa imagem, foi possível elaborar os mapas de hipsometria, declividade e modelo digital de terreno.

Os dados geológicos foram compilados da carta geológica adquirida na Companhia de Pesquisa e Recursos Minerai (OLIVEIRA, 1994). Além disso, foi elaborado esboço de solos na escala 1:100.000 utilizando-se a técnica de análise cartográfica conjunta dos mapas de geologia (OLIVEIRA, 1994), pedologia em escala 1:250.000 (SIEG/SIC), hipsometria e declividade. Esse esboço de solos foi feito até o primeiro nível categórico e as informações foram validadas em 
campo com a identificação de perfis representativos dos solos mapeados.

Para a elaboração do mapa de suscetibilidade à erosão laminar foi utilizada a metodologia de Salomão (1999). A metodologia utilizada para a elaboração do esboço de suscetibilidade à erosão linear foi baseada nas metodologias utilizadas por Arcaya (2007), Sena (2008) e Salomão (1999). Para a identificação das áreas de suscetibilidade à erosão linear, foram utilizados os seguintes atributos: geologia, declividade, pedologia e uso e cobertura do solo, sendo feita a atribuição de pesos pra cada atributo com base em níveis de importância.

\section{Resultados e Discussões}

As cotas altimétricas da área estudada variam de 850 a 1040 metros respondendo por uma amplitude altimétrica de 190 metros. A classe altimétrica que predomina na bacia é de 910 a 940 metros, representando quase $20 \%$ da área, seguido das cotas de 940 a 970 metros, isso mostra que nessa região predominam altitudes médias. No que se refere a declividade, foi possível analisar que a área de estudo possui um relevo predominantemente plano, onde prevalecem declividades que variam de $0 \%$ a $3 \%, 3 \%$ a $6 \%$ e $6 \%$ a $12 \%$, equivalendo a maior parte da área estudada o que indica que a bacia do córrego Pedrinhas é considerada plana e segundo Ross (1994) essa paisagem configura fragilidades que variam de muito fraca a fraca. Já as maiores declividades que variam de $12 \%$ a $20 \%, 20 \%$ a $25 \%$ e $>25 \%$ referem-se a pouco mais de $25 \%$ da área total estudada e $35 \%$ da bacia, configurando nesses locais uma fragilidade que varia de média a forte segundo a classificação de Ross (1994).

As classes de solo cartografadas na área de estudo foram: Plintossolo, Latossolo, Gleissolo e Associação de Cambissolo com Argissolo. O solo que predomina no retângulo envolvente é o Plintossolo que cobre 47,2\% da área estudada e 37,6\% da bacia e estão associados a topos altos e planos. Os Latossolos estão associados as vertentes de baixa e média declividade recobrindo uma área total de 38,5\% e tem maior representatividade na bacia com $43,4 \%$. Nas cabeceiras de drenagem e baixas vertentes tem a associação de Cambissolo com Argissolo onde predominam as declividades superiores a $20 \%$. Os Gleissolos ocorrem ao longo dos canais de drenagem, nas planícies de inundação e representam cerca de $4 \%$ da área estudada.

As áreas de preservação permanente representam pouco mais 5,0\% da área total estudada. O tipo de uso que predomina nas áreas de APP (área de preservação permanente) é o de formação florestal com $81,4 \%$ do retângulo envolvente e 70,6\% da bacia. Entretanto, os outros 18,6\% da área estudada e $29,4 \%$ da bacia estão sendo utilizados para fins como agricultura, pastagem e 


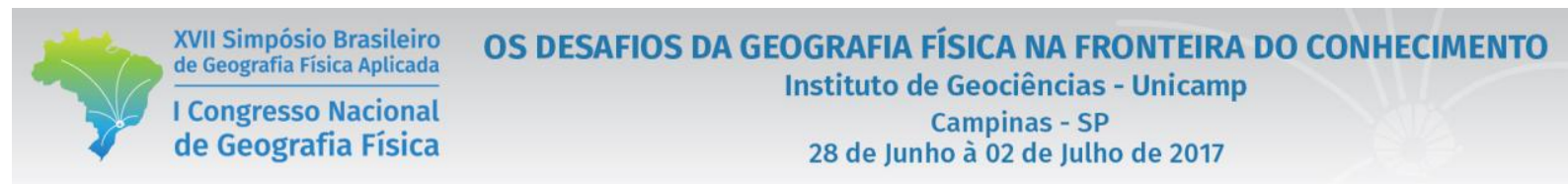

urbanização.

O mapa de suscetibilidade à erosão laminar (Figura 2) indica três classes de suscetibilidade: classe I - Extremamente Suscetível representando 10,3\% do retângulo envolvente e $15,2 \%$ da bacia, áreas destacadas em vermelho no mapa; classe IV - Pouco Suscetível contemplando a maioria da área de estudo com $85,7 \%$ e $81,3 \%$ da bacia representada pela cor verde claro; e a classe V - Pouco a Não Suscetível que refere-se a área com menor percentual sendo de $4 \%$ no retângulo envolvente e apenas $3,5 \%$ do total da bacia indicado pela cor verde escuro.

O esboço de suscetibilidade à erosão linear (Figura 3) foi elaborado com base na distribuição de pesos às classes temáticas (SALOMÃO, 1999) e com a ponderação de cada tema utilizando a operação entre mapas. Vale destacar que o esboço do mapa apresenta as menores suscetibilidades para maiores valores e as maiores suscetibilidades para os menores valores.
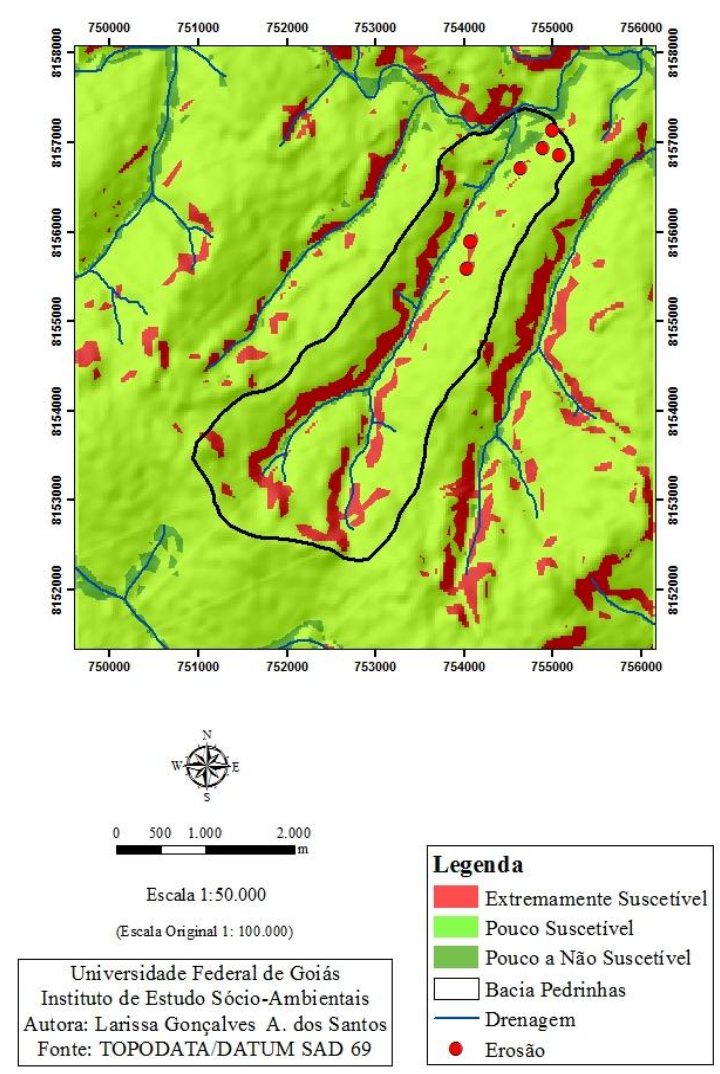

Figura 2: Mapa de Suscetibilidade à erosão laminar da bacia do córrego Pedrinhas.
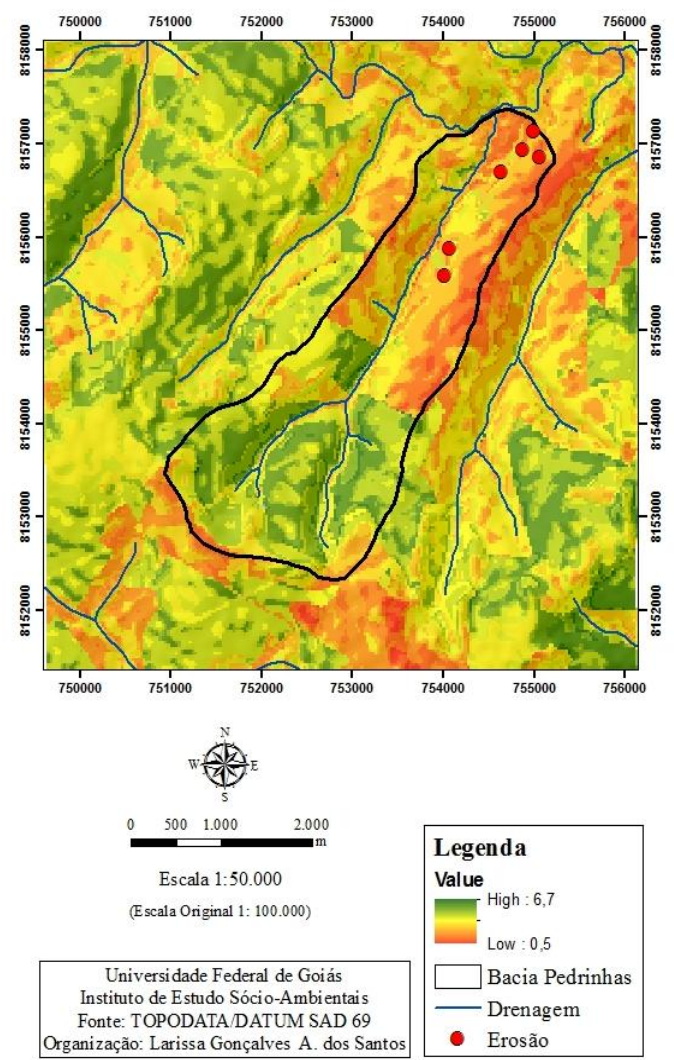

Figura 3: Mapa de Suscetibilidade à erosão linear da bacia do Córrego Pedrinhas.

As suscetibilidades mais altas com relação a erosão laminar estão localizadas na porção central do mapa correspondendo exatamente onde está situada a área urbana. Mesmo que estejam em áreas relativamente planas, o uso do solo foi determinante nesse resultado, pois na geração desse 
modelo o tema uso do solo recebeu um peso maior. Essas altas suscetibilidades estão associadas também com o uso da agricultura, solo exposto e pastagem observadas ao Sul e Sudoeste da área.

Já os locais com suscetibilidade mais baixa estão presentes na região Noroeste e Sudeste do mapa, correspondendo às declividades médias, também com o uso da pastagem e formação florestal. As formações florestais colaboram para a proteção da camada superficial do solo, absorvendo as águas das chuvas através de suas raízes onde ocorre a infiltração, inibindo o contato direto da água das chuvas na superfície que podem remover as partículas de solo colaborando com o surgimento dos processos erosivos.

\section{Considerações Finais}

Quanto a suscetibilidade à erosões laminares, constatou-se que mais de $80 \%$ da área estudada correspondem a locais de baixa suscetibilidade enquadrando-se dentro da classe pouco suscetível referentes aos locais mais planos. Já as áreas de maior suscetibilidade laminar estão relacionadas às declividades mais acentuadas.

No que se refere a suscetibilidade à erosão linear, a maior suscetibilidade não teve uma relação direta com altas declividades, mas sim com o tipo uso do solo. Construção de ruas longas no sentido do declive, lançamento de águas pluviais à meia encosta e cabeceira de drenagem e ocupação das áreas de preservação permanente estão potencializando o surgimento de erosões lineares mesmo em área com declividades mais moderadas.

\section{Bibliografia}

AFFONSO, Marcus V. T. Cadastro de erosões na área urbana do município de Silvânia - GO. Goiânia: UFG, 2014.

ARCAYA, Salomé G. C. Avaliação dos fatores condicionantes dos processos erosivos no Distrito Federal. Dissertação de Mestrado. Brasília: Universidade de Brasília, 2007.

CASTRO, Selma S. de; XAVIER, Luciano de S. Plano de controle da erosão linear da área de abrangência das nascentes dos rios Araguaia e Araguainha - GO e MT. Goiânia, 2004.

Instituto de Pesquisas Tecnológicas. Curso de Geologia Aplicada ao meio ambiente. São Paulo, 1995.

JESUS, Andrelisa S. Processos Erosivos em Silvânia - GO. Goiânia, 2014.

MOREIRA, Ceres V. R; PIRES NETO, A. G. Clima e Relevo. In: OLIVEIRA, A. M. dos S; BRITO, S. N. A. de. (Org.). Geologia de Engenharia. São Paulo: Associação Brasileira de Geologia de Engenharia, 1998. Cap. 5.

OLIVEIRA, Cipriano C. de. Programa Levantamentos Básicos do Brasil - Folha SE.22-X-B-V, Leopoldo de Bulhões: Brasília: DNPM, 1994. 


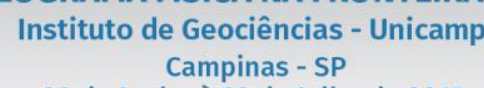

ROSS, J. L. S. Análise empírica da fragilidade dos ambientes naturais e antropizados. São Paulo, 1994.

SALOMÃO, Fernando X. T. Controle e prevenção dos processos erosivos. In: GUERRA, T.A.J.; SILVA, A.S. \& BOTELHO, R.G. (Org.). Erosão e Conservação dos solos: conceitos, temas e aplicações. Rio de Janeiro: Bertrand Brasil, 1999. Cap. 7.

SENA, Júlio N. O uso de sistema de informação geográfica na avaliação de diferentes alternativas de geração de cartas de suscetibilidade à erosão. Dissertação de Mestrado. Ilha Solteira: Universidade Estadual Paulista, 2008. 